\title{
Influence of pulp condition on the accuracy of an electronic foramen locator in posterior teeth: an in vivo study
}

\section{Daniel Renner ${ }^{(a)}$ \\ Renata Grazziotin-Soares ${ }^{(b)}$ Giulio Gavini(c) \\ Fernando Branco Barletta ${ }^{(b)}$}

(a) Department of Endodontics, School of Dentistry, Santa Cruz do Sul University, Santa Cruz do Sul, RS, Brazil.

(b) Department of Restorative Dentistry, School of Dentistry, Lutheran University of Brazil, Canoas, RS, Brazil.

(c) Department of Endodontics, School of Dentistry, University of São Paulo, São Paulo, SP, Brazil.
Declaration of Interests: The authors certify that they have no commercial or associative interest that represents a conflict of interest in connection with the manuscript.

Corresponding author:

Renata Grazziotin-Soares

E-mail: regrazziotin@gmail.com

Received for publication on Oct 12, 2011 Accepted for publication on Jan 10, 2012

\begin{abstract}
The aim of this study was to assess, in vivo, the accuracy of the NovApex ${ }^{\circledR}$ electronic foramen locator in determining working length (WL) in vital and necrotic posterior teeth. The NovApex ${ }^{\circledR}$ was used in 144 canals: 35 teeth with vital pulps (68 canals) and 42 teeth with necrotic pulps (76 canals). WL was measured with the NovApex ${ }^{\circledR}$ locator and confirmed using the radiographic method. Differences between electronic and radiographic measurements ranging between 0.0 and 0.4 millimeters were classified as acceptable; differences equal to or greater than 0.5 millimeter were considered unacceptable. Pearson's chi-square test was used to assess the influence of pulp condition on the accuracy of NovApex ${ }^{\circledR}(\alpha=0.05)$. Regardless of pulp condition, differences between electronic and radiographic WL measurements were acceptable in $73.61 \%$ of the canals. No statistically significant differences in accuracy were observed when comparing vital and necrotic canals $(\mathrm{p}>0.05)$. There were 38 unacceptable measurements. In none of these cases was the file tip located beyond the radiographic apex; in 32, it was located short of the NovApex ${ }^{\circledR}$ measurement. Pulp condition had no significant effect on the accuracy of NovApex ${ }^{\circledR}$.
\end{abstract}

Descriptors: Endodontics; Tooth Apex; Root Canal Therapy.

\section{Introduction}

Precise working length (WL) measurement is an essential step in root canal treatment. ${ }^{1}$ The apical constriction (minor foramen) coincides with the pulp-periodontal junction and is therefore considered to be the ideal endpoint for root canal cleaning, shaping, and filling. ${ }^{1}$ In an in vitro study designed to determine the exact location of the apical constriction, Kuttler $^{2}$ found that the apical constriction was microscopically visible in $96 \%$ of the cases, located between 0.524 and 0.659 millimeters $(\mathrm{mm})$ short of the apical foramen. Mean distances from the apex to the foramen (A-F) and from the apex to the constriction (A-C) were measured by Dummer et al. ${ }^{3}$ The authors evaluated 270 extracted human teeth and found a mean A-F distance of $0.38 \mathrm{~mm}$ and a mean A-C distance of $0.89 \mathrm{~mm}$.

WL can be determined radiographically or electronically. The radiographic method, traditionally the most popular way to measure WL in 
endodontics, ${ }^{4-13}$ has some advantages, e.g. the possibility to study root canal anatomy and to identify periapical lesions, as reported by ElAyouti et al. ${ }^{14}$ Conversely, one disadvantage of this method is related to the difficulties involved in locating the apical foramen and the apical constriction.

In addition to the well-established radiographic method, several electronic foramen locators (EFLs) have been introduced on the market with the aim of improving WL determination. Early resistancebased EFLs proved inaccurate in the presence of conducting fluids. ${ }^{8,15}$ Other types of EFLs work with alternating currents and are therefore compatible with different fluids present inside the root canal. ${ }^{16}$ Recently, many authors, using different research designs, have attested to the accuracy of several EFL models. ${ }^{12,13,17-20}$

One of the EFLs currently available is the NovApex $^{\circledR}$ (Forum Engineering Technologies Ltd., Rishon Lezion, Israel) that operates based on the impedance principle, i.e., it uses alternating current of two or more frequencies while maintaining a fixed difference or ratio between the frequencies. ${ }^{21}$ In other words, based on electrical properties (e.g. impedance), these EFLs are able to detect the point at which the file leaves the root canal and enters the periodontal ligament (apical constriction). ${ }^{22,23}$

Impedance-based EFLs allow measuring WL, regardless of the type of electrolyte found in the root canal. Arora and Gulabivala, ${ }^{24}$ in an in vitro study, showed that the Endex locator was accurate in the presence of sodium hypochlorite, unlike the RCM Mark II. Similarly, other authors have demonstrated that the presence of irrigating solutions did not interfere with EFL performance in extracted teeth. ${ }^{17,25}$

In addition to the influence of fluids and solutions, the influence of pulp condition on the accuracy of EFLs has been increasingly investigated. In vivo studies using teeth scheduled for extraction showed no differences in EFL measurements between vital and necrotic teeth. ${ }^{5-7}$ Similar results have been obtained in clinical studies that used radiographic analysis as a comparison method. Smadi, ${ }^{9}$ for example, tested the effect of preoperative pulp status on the behavior of the TAZX foramen locator and did not find statistical differences in the mean distance from the tip of the root filling to the radiographic apex between vital and non-vital canals. Similarly, Akisue et al. ${ }^{10}$ showed that the Elements Diagnostic Unit and Apex Locator was reliable regardless of pulp vitality.

To date, few studies have reported on the accuracy of the NovApex ${ }^{\circledast}$ locator. Although some in vitro $^{19,21,26,27}$ and in vivo ${ }^{11}$ studies are available, neither has focused on the possible influence of pulp condition on the accuracy of this EFL. The null hypothesis of our study was that the NovApex ${ }^{\circledR}$ would be accurate in both vital and necrotic teeth.

Therefore, the objective of this study was to assess in vivo the influence of pulp condition (vital $v s$. necrotic pulp) on the accuracy of NovApex ${ }^{\circledR}$ in posterior teeth.

\section{Methodology}

This study was approved by the local Ethics Committee (Institutional Review Board-equivalent). Informed written consent forms were signed by all patients included in the study.

Cases were selected between March and July 2008 at the Santa Cruz do Sul University (UNISC), southern Brazil. Any patient aged 12 to 65 years seeking primary endodontic treatment of posterior teeth was considered eligible for the study. The first tooth requiring endodontic treatment was selected for analysis from each patient.

Teeth with previous endodontic treatment, or presenting resorption (visible on radiographs), calcification, metal restoration, prosthesis, a post or a cast post and core, or incomplete root formation were excluded. Pulp sensibility was assessed using Endo-Ice refrigerant spray (Hygenic Corp., Akron, USA). Results were recorded as either vital or necrotic after the pulp was accessed and vascular status was determined.

Sample size was defined based on previous clinical studies., ${ }^{4-11}$ A total of 144 canals were selected; 35 teeth (68 canals) were diagnosed as vital, and 42 teeth (76 canals) as necrotic.

The following root canals were analyzed:

- buccal and palatal canals of maxillary first premolars;

- single canal of mandibular first premolars; 
- single canal of maxillary second premolars;

- single canal of mandibular second premolars;

- mesiobuccal, distobuccal and palatal canals of maxillary first and second molars; and

- mesiobuccal and distal canals of mandibular first and second molars.

During endodontic treatment, patients were anaesthetized, a rubber dam was placed, and the coronal/middle third of each canal was flared using rotary Sx and S1 files (ProTaper Universal, Dentsply/ Maillefer, Ballaigues, Switzerland). Teeth were irrigated with $3 \mathrm{~mL}$ of $1 \% \mathrm{NaOCl}$ after the use of each rotary instrument, and excess solution was removed from the pulp chamber using aspirators. All steps were conducted by an experienced endodontic specialist, previously trained in the use of NovApex ${ }^{\circledR}$.

The procedure for using the NovApex ${ }^{\circledR}$ EFL was as follows: a clip was placed on the patient's lip, and a K-FlexoFile (Dentsply/Maillefer, Ballaigues, Switzerland) was selected according to the apical size of each canal and attached to the EFL. The file was gently inserted into the root canal until the display read 0.0. The file was then withdrawn coronally until the display showed a stable reading of 1.0.

Measurements obtained with the NovApex ${ }^{\circledR}$ were compared with those obtained using the conventional radiographic method, as described below.

Radiographs were scanned (ColorPage-HR7X Slim, Genius, Taipei, Taiwan) in full size and at $600 \mathrm{dpi}$ resolution. Images were stored in a personal computer and transferred to Adobe Photoshop CS2 software, version 9.0 (Adobe Systems Inc., San Jose, USA). Images were converted into millimeters based on the original radiographic images. Resolution was held constant at 600 dpi to preserve image sharpness. Afterwards, a researcher experienced in the use of the software used the ruler tool to define the distance between the file tip and the radiographic apex of the root.

In the comparison between electronic and radiographic measurements $(1.0 \mathrm{~mm}$ short of the radiographic apex), differences ranging from 0.0 to $0.4 \mathrm{~mm}$ were classified as acceptable, whereas differences equal to or greater than $0.5 \mathrm{~mm}$ were considered unacceptable.

The Pearson chi-square test was used to assess the relationship between pulp condition (vital or necrotic) and NovApex ${ }^{\circledR}$ accuracy results. Data were analyzed using the Statistical Analysis System (SAS), version 8.2 (SAS Institute, Cary, USA). Significance was set at $\mathrm{p}<0.05$.

\section{Results}

Differences between the two measurement methods (EFL and radiography) are shown in Table 1. Considering the 144 canals submitted to measurement, 73.61\% (106/144) showed acceptable differences between the two measurements. The Pearson chi-square test revealed no significant influence of pulp condition on measurement accuracy ( $\mathrm{p}>0.05)$.

Of the 38 unacceptable measurements obtained (difference $\geq 0.5 \mathrm{~mm}$ ), there was no case where the file tip was located beyond the radiographic apex, and 32 cases where it was located short of the NovApex $^{\circledR}$ measurement. Short measurements occurred in 16/20 necrotic canals and in 16/18 vital canals.

\begin{tabular}{|c|c|c|c|c|c|}
\hline \multirow{7}{*}{$\begin{array}{r}\text { Table } 1 \text { - Influence of pulp } \\
\text { condition on the accuracy of } \\
\text { NovApex }{ }^{\circledR} .\end{array}$} & $\begin{array}{l}\text { Measurement } \\
\text { difference }(\mathrm{mm})\end{array}$ & $\begin{array}{l}\text { Total frequency } \\
(\%)\end{array}$ & $\begin{array}{c}\text { Number of necrotic } \\
\text { canals* }(\%)\end{array}$ & $\begin{array}{l}\text { Number of vital } \\
\left.\text { canals** }^{*} \%\right)\end{array}$ & $P$ value \\
\hline & 0.0 & $15(10.42)$ & 9 (1 1.84) & $6(08.82)$ & 0.6388 \\
\hline & 0.1 & 25 (17.36) & 15 (19.74) & 10 (14.71) & 0.4504 \\
\hline & 0.2 & 32 (22.22) & $16(21.05)$ & $16(23.53)$ & 0.8015 \\
\hline & 0.3 & $18(12.50)$ & 8 (10.53) & 10 (14.71) & 0.4983 \\
\hline & 0.4 & $16(11.11)$ & 8 (10.53) & 8 (1 1.76$)$ & 0.9588 \\
\hline & $\geq 0.5$ & 38 (26.39) & $20(26.32)$ & $18(26.47)$ & 0.8915 \\
\hline
\end{tabular}




\section{Discussion}

The NovApex ${ }^{\circledast}$ locator has been evaluated in vivo $^{11}$ and also in in vitro models. ${ }^{19,21,26,27}$ The present in vivo study adds to the existing body of knowledge by reporting data regarding accuracy obtained under authentic clinical conditions.

All measurements were conducted by the same experienced and trained operator, thus eliminating the possibility of operator bias. Although the issue of how the operator's skill influences EFL accuracy has not yet been described in the literature, extensive training and practice are required to ensure familiarity with these devices and consequently accurate measurements, as reported by Akisue et al. ${ }^{10}$ Other measures taken to ensure a standardized and reliable data collection process included the use of stainless steel $\mathrm{K}$ files, based on previous studies that have failed to show greater accuracy of nickel-titanium files, ${ }^{15,20}$ as well as the selection of files according to each canal size. Ebrahim et al., ${ }^{28}$ based on the results of an ex vivo study, recommended that root canal diameter should be estimated first, and then a snug-fitting file should be used for EFL root canal length determination. The clinical study conducted by Akisue et al. ${ }^{10}$ also used files compatible with the size of each canal.

In the present study, the NovApex ${ }^{\circledR}$ locator showed similar accuracy results $(\mathrm{p}>0.05)$ in both vital and necrotic posterior teeth, confirming our null hypothesis. Although some authors ${ }^{8,24}$ have demonstrated a higher accuracy of EFLs in determining WL in vital canals, when compared with necrotic canals, the identical accuracy found in our sample regardless of pulp condition is in agreement with other studies. ${ }^{5-7,9,10}$

The rate of acceptable measurements (73.61\%), considering both vital and necrotic pulps, indicates that the NovApex ${ }^{\circledR}$ EFL is accurate and useful to determine WL under clinical circumstances. In 106/144 canals, the difference between the NovApex $^{\circledR}$ and the radiographic measurement was between 0.0 and $0.4 \mathrm{~mm}$. As a parameter for our results, the in vivo study by Chevalier et al. ${ }^{11}$ found $91.3 \%$ of acceptable measurements with the NovApex ${ }^{\circledR}$ when compared with the radiographic method. However, these authors used the 0.5 mark on the EFL display, and measurements between 0 and $2 \mathrm{~mm}$ from the radiographic apex were considered acceptable. In the present study, a lower tolerance was used, which can probably explain the lower percentage of acceptable measurements obtained. In addition, the fact that our sample was comprised exclusively of posterior teeth, including 110 canals of molars, may account for the lower accuracy observed. This hypothesis is supported by the results of Vieyra and Acosta, ${ }^{13}$ who used four EFL models to determine the apical constriction in vivo, subsequently confirming its location after tooth extraction, and who found a lower percentage of precise measurements in premolars and molars when compared with anterior teeth.

The need to select a tolerance factor in analyzing EFL accuracy hinders direct comparisons between in vitro and in vivo results. Nevertheless, the tolerance rate plays a fundamental role in clinical practice, where it is often not possible to locate the apical constriction precisely, i.e., the ideal WL. ${ }^{2}$ In the in vitro study conducted by D'Assunção et al., ${ }^{19}$ for example, none of the 31 electronic measurements performed with the NovApex ${ }^{\circledR}$ coincided exactly with the actual apical constriction, suggesting poor locator accuracy. However, according to these authors, a comparison of their results with the mean distances observed between the file tip and the apical constriction would yield more accurate findings, since all their electronic measurements lay within the acceptable range of $\pm 0.5 \mathrm{~mm}$. According to ElAyouti and Lost, ${ }^{29}$ although this difference may affect the results of laboratory studies, it is not clinically relevant. The present study used a tolerance rate of 0.0 to $0.4 \mathrm{~mm}$, which is in agreement with the clinical study of Akisue et al. ${ }^{10}$

A relevant finding of this study was the great number of short measurements found among the unacceptable results. Short instrumentation of the root canal may pose problems for the adequate treatment of necrotic teeth, since the prognosis of these teeth depends on the successful elimination of microorganisms in infected root canals. ${ }^{30}$ One possible reason for the short measurements observed in our study could be the use of the $1.0 \mathrm{~mm}$ mark to determine WL (rather than 0.0, as recommended 
by Nekoofar et al. ${ }^{23}$ for the location of the apical constriction). Further studies are warranted to investigate the accuracy of NovApex ${ }^{\circledR}$ using different marks on the locator display.

\section{Conclusion}

Under clinical conditions, the WL values obtained in our study with the NovApex ${ }^{\circledR}$ EFL showed

\section{References}

1. Ricucci D, Langeland K. Apical limit of root canal instrumentation and obturation, part 2. A histological study. Int Endod J. 1998 Nov;31(6):394-409.

2. Kuttler Y. Microscopic investigation of root apexes. J Am Dent Assoc. 1955 May;50(5):544-52.

3. Dummer PMH, McGinn JH, Rees DG. The position and topography of the apical canal constriction and apical foramen. Int Endod J. 1984 Oct;17(4):192-8.

4. Frank AL, Torabinejad M. An in vivo evaluation of Endex electronic apex locator. J Endod. 1993 Apr;19(4): 177-9.

5. Mayeda DL, Simon JH, Aimar DF, Finley K. In vivo measurement accuracy in vital and necrotic canals with the Endex apex locator. J Endod. 1993 Nov;19(11):545-8.

6. Dunlap CA, Remeikis NA, BeGole EA, Rauschenberger CR. An in vivo evaluation of an electronic apex locator that uses the ratio method in vital and necrotic canals. J Endod. 1998 Jan;24(1):48-50.

7. Lee SJ, Nam KC, Kim YJ, Kim DW. Clinical accuracy of a new apex locator with an automatic compensation circuit. J Endod. 2002 Oct;28(10):706-9.

8. Pommer O, Stamm O, Attin T. Influence of the canal contents on the electrical assisted determination of the length of root canals. J Endod. 2002 Feb;28(2):83-5.

9. Smadi L. Comparison between two methods of working length determination and its effect on radiographic extent of root canal filling: a clinical study [ISRCTN71486641]. BMC Oral Health. 2006 Feb 11;6:4. doi:10.1186/1472-6831-6-4.

10. Akisue E, Gavini G, de Figueiredo JA. Influence of pulp vitality on length determination by using the Elements Diagnostic Unit and Apex Locator. Oral Surg Oral Med Oral Pathol Oral Radiol Endod. 2007 Oct;104(4):129-32.

11. Chevalier V, Arbab-Chirani R, Nicolas M, Morin V. Occurrence of no-function of two electronic apex locators: an in vivo study. Oral Surg Oral Med Oral Pathol Oral Radiol Endod. 2009 Dec;108(6):61-5.

12. Ravanshad S, Adl A, Anvar J. Effect of working length measurement by electronic apex locator or radiography on the adequacy of final working length: a randomized clinical trial. J Endod. 2010 Nov;36(11):1753-6. a $73.61 \%$ agreement rate with those determined radiographically. Pulp condition had no significant effect on the accuracy of the NovApex ${ }^{\circledR}$. These results underscore the accuracy of NovApex ${ }^{\circledR}$ and allow recommending its use for WL determination in endodontic therapy, in both vital and necrotic posterior teeth.

13. Vieyra JP, Acosta J. Comparison of working length determination with radiographs and four electronic apex locators. Int Endod J. 2011 Jun;44(6):510-8.

14. ElAyouti A, Weiger R, Lost C. Frequency of overinstrumentation with an acceptable radiographic working length. J Endod. 2001 Jan;27(1):49-52.

15. Nekoofar MH, Sadeghi K, Sadighi Akha E, Namazikhah MS. The accuracy of the Neosono Ultima EZ apex locator using files of different alloys: an in vitro study. J Calif Dent Assoc. 2002 Sep;30(9):681-4.

16. Foster K, Schwan H. Dielectric properties of tissues and biological materials: a critical review. Crit Rev Biomed Eng. 1989;17(1):25-104.

17. Carvalho AL, Moura-Netto C, Moura AA, Marques MM, Davidowicz H. Accuracy of three electronic apex locators in the presence of different irrigating solutions. Braz Oral Res. 2010 Oct-Dec;24(4):394-8.

18. Cianconi L, Angotti V, Felici R, Conte G, Mancini M. Accuracy of three electronic apex locators compared with digital radiography: an ex vivo study. J Endod. 2010 Dec;36(12):20037.

19. D’Assunção FL, Albuquerque DS, Salazar-Silva JR, Dos Santos VC, Sousa JC. Ex vivo evaluation of the accuracy and coefficient of repeatability of three electronic apex locators using a simple mounting model: a preliminary report. Int Endod J. 2010 Apr;43(4):269-74.

20. Sadeghi S, Abolghasemi M. The accuracy of the Raypex5 electronic apex locator using stainless-steel hand K-file versus nickel-titanium rotary Mtwo file. Med Oral Patol Oral Cir Bucal. 2010 Sep 1;15(5):788-90.

21. D’Assunção FL, de Albuquerque DS, de Queiroz Ferreira LC. The ability of two apex locators to locate the apical foramen: an in vitro study. J Endod. 2006 Jun;32(6):560-2.

22. Nekoofar MH. Electronic apex locators. Int Endod J. 2005 Jun;38(6):417-8; author reply 418.

23. Nekoofar MH, Ghandi MM, Hayes SJ, Dummer PMH. The fundamental operating principles of electronic root canal length measurement devices. Int Endod J. 2006 Aug;39(8):595609. 
24. Arora RK, Gulabivala K. An in vitro evaluation of the Endex and RCM Mark II electronic apex locators in root canals with different contents. Oral Surg Oral Med Oral Pathol Oral Radiol Endod. 1995 Apr;79(4):497-503.

25. Meares WA, Steiman HR. The influence of sodium hypochlorite irrigation on the accuracy of the Root ZX electronic apex locator. J Endod. 2002 Aug;28(8):595-8.

26. Goldberg F, Marroquín BB, Frajlich S, Dreyer C. In vitro evaluation of the ability of three apex locators to determine the working length during retreatment. J Endod. 2005 Sep;31(9):676-8.

27. Goldberg F, Frajlich S, Kuttler S, Manzur E, Briseño-Marroquín B. The evaluation of four electronic apex locators in teeth with simulated horizontal oblique root fractures. J Endod. 2008 Dec;34(12):1497-9.

28. Ebrahim AK, Wadachi R, Suda H. Ex vivo evaluation of the ability of four different electronic apex locators to determine the working length in teeth with various foramen diameters. Aust Dent J. 2006 Sep;51(3):258-62.

29. ElAyouti A, Lost C. A simple mounting model for consistent determination of the accuracy and repeatability of apex locators. Int Endod J. 2006 Feb;39(2):108-12.

30. Rôças IN, Siqueira Jr JF. In vivo antimicrobial effects of endodontic treatment procedures as assessed by molecular microbiologic techniques. J Endod. 2011 Mar;37(3):304-10. 